\title{
Support of the supporters
}

\author{
F. Stiefel
}

Received: 23 July 2007 / Accepted: 16 October 2007 / Published online: 13 November 2007

(C) Springer-Verlag 2007

\begin{abstract}
Background A growing body of evidence indicates that health care professionals working with severely ill patients are in need of support. Beside "external" factors, such as heavy clinical patient volume or administrative duties, "intra-psychic stressors," related to the inner significance of contextual factors, are an important source of clinician's distress. Identification of and working through intrapsychic stressors can considerably reduce psychological distress and thus provide effective and long-lasting support of the oncology clinician.

Purpose This article discusses key elements of intrapsychic stressors, namely (1) emotions towards the patient, (2) awareness of own limits, (3) confusion about empathy, identification, counter-transference and collusion, (4) the influence of early development and life trajectory on career choices and professional identity and (5) the conflicting roles a health care professional being in need of support has to face.
\end{abstract}

Keywords Supervision · Liaison psychiatry ·

Healthcare professionals $\cdot$ Support

This paper was presented as key note lecture at the MASC-ISOO 20th Anniversary International Symposium Supportive Care in Cancer in St-Gallen, June 2007.

F. Stiefel $(\bowtie)$

Chef de Service, Psychiatrie de Liaison,

Centre Hospitalier Universitaire Vaudois (CHUV),

Rue de Bugnon 21,

1006 Lausanne, Switzerland

e-mail: Frederic.Stiefel@chuv.ch
Different persons, such as family members or volunteers, support cancer patients in distress; among them are also healthcare professionals to whom this article is addressed. As other supporters, professional supporters are in need of support as indicated by studies showing that up to $30 \%$ of medical oncologists suffer from psychiatric morbidity, which is nearly as twice as much prevalence as identified in the general population; research on burnout found that up to one third of cancer clinicians report high levels of emotional exhaustion and demotivation and low levels of perception of personal achievement [1].

In a recent paper, Shanafelt et al. [2] reported that oncology clinicians are stressed by heavy clinical patient volume, unpredictable work schedules, exposure to suffering and death and administrative duties. This article, however, will not focus on "external" aspects of professional stress, such as working hours or patient volume, but on intra-psychic stressors, which emerge as a result of psychological tensions triggered by the significance of an external event. The literature on intra-psychic stressors is rather scarce, probably because such studies are difficult to conduct given the sensitivity of the data and the psychological insight required from study subjects. However, intra-psychic stressors are a key for understanding workrelated stress, as they provide the link between the "outer" and "inner" world of the clinician. As Graham and Ramirez [3] stated: "Although general factors associated with poor mental health have been identified, it remains unclear why some consultants are able to tolerate stress, whereas others suffer harm to their mental health."

This is illustrated by an oncology clinician who participated in a communication skills training [4] and reported the following situation during an individual supervision with the author of this manuscript. Being on call, this 36-year-old physician was asked to see an elderly 
patient, suffering from advanced breast cancer, who complained about pain because of bone metastases. Her complaints and simultaneous refusal of any pain medication infuriated the oncology clinician to a point that she started to shout at her, insisting that a patient cannot complain and at the same time refuse analgesics. The first part of the supervision aimed to understand how an "unreasonable behaviour" of a patient can be understood as meaningful (threatening thoughts concerning pain medication etc.). Then, the oncology clinician was invited to report more on her emotions and how she explained her strong reaction. She reported that she not only felt anger and rage against this patient but also an intense anxiety, which she related to her own medical history. Indeed, she had been successfully operated for a melanoma 3 years ago and stated "If I wouldn't have followed the doctors' advice, I wouldn't be alive any more."

This supervision illustrates the link between context and significance or between "external" and "intra-psychic" stressors. Key elements of intra-psychic stressors will now be discussed, illustrated by further aspects of this supervision, which continued for three more times after this first session. Identification of and working through intra-psychic stressors can considerably reduce work-related distress and is therefore an important strategy for effective and longlasting support of the oncology clinician.

\section{Emotions towards the patient—-"no censorship"}

Patient encounters evoke thoughts and feelings in the clinician, which are mot restricted to the clinical situation. Sometimes, these feelings are comfortable, but sometimes they may be difficult to deal with and stressful. So-called negative emotions arising in the clinician are often anxiety provoking and therefore suppressed. However, they do exist and influence the clinician unconsciously when denied by feelings of shame or guilt. As Holmes [5] stated in an article of the British Medical Journal: "Have we not all sometimes felt bored and irritated by certain patients, longing for the consultation to end? Can any doctor honestly say that he or she has never felt a flicker of sexual interest in a patient? Have we never imagined the death of a certain patient and the relief that would bring, not just to them but to us, their impotent carers?"

Emotions, especially uncomfortable emotions, should not just be perceived as "negative side effects" of daily clinical work but should be welcomed as valuable pieces of information, which reveal important aspects of the patient clinician relationship. Such emotions are often suppressed because of a confusion between "feelings," "thoughts" and "deeds." While there is a difference between them and society does not judge them in the same manner, on a personal level, feelings and thoughts may be perceived as being the same as deeds and are then censored by our mind. However, the more we are aware of our emotions, the less we are emotion-driven and able to perceive a given situation adequately. This is illustrated by the supervision mentioned above during which the oncology clinician stated that she "can't stand to feel angry towards a patient." This censorship of feelings towards a patient hampered her understanding that the problems provoked by the clinical situation were closely related to her own life trajectory.

\section{To be aware of and accept limits_-"you can't have it all"}

To be aware of the limits of the medical power and of our own possibilities is another important element of stress reduction. Too often health care professionals have high demands on themselves and a great difficulty to respect their own limits. Winnicott reminded us with his concept of the "good-enough mother," that we cannot ask for and we do not have to be "perfect mothers." It is sufficient to be a good-enough mother who provides adequate care and is sensitive to the infant's needs [6]. In the health care domain, our duty is to cure patients and to care for those we cannot cure. If we ignore these limits, we expose our patients and ourselves to a danger illustrated by a citation attributed to Hannah Arendt: "It seems that we are subjected to a magic formula, which provides us with the capacity to do the impossible under the condition to loose the capacity to do the possible."

In the second session of the abovementioned supervision, the oncology clinician stated that after her operation of the melanoma, she immediately started working again, although she felt very exhausted. While discussing this situation, she recognised how absurd it was that she did not accept a sick leave for herself while prescribing it on a daily basis to her patients. She also indicated that she had a great difficulty to accept "that there are limits to curative treatment," despite the fact that she intellectually understands how important it is in oncology "to know when to switch from curative to palliative care."

\section{Between ego and ego ideal-"I am and I wished to be"}

As anybody else, health care professionals not only have an "ego" capable of reasoning but also an ego ideal, which harbours our wish how we would like to be. The ego ideal is a strong source of motivation but also of tension and exhaustion if an important discrepancy exists between the ego ideal and the ego. During a professional career, the process of deconstructing ego ideals is painful but necessary and liberating, as it allows the clinician to be in 
harmony with his capacities and not to struggle with becoming someone else who he is simply not capable to be.

In the third session of the abovementioned supervision of the oncology clinician, it became quite clear that she had strong convictions of how a "good oncologist" has to be, and she aimed to reach these ideals without taking into account, for example, that she temporarily should have slowed down because of her medical illness. She was then able to question her ambitions and to somehow reduce the tensions because of the discrepancy between her ego ideal and her ego.

\section{Empathy for the patient- "sometimes it's not empathy, but one only shares a common problem"}

Relationships between patients and health care professionals may be associated with strong feelings. Some are related to the empathic response, which can be defined as "understanding, being aware of, being sensitive to and experience the feelings and thoughts of another." Empathy, however, also implicates that one is not only able to feel close to a patient but also to take distance again and concentrate on oneself. Similar feelings may exist in moments of identification, which can be defined as a lack of distinction from another, leading to the experience of "being the other." Identification emerges in situations where certain features of the patient produce a strong echo in the clinician (same age, features of a loved one, etc.). Identification is stressful for the clinician and hampers his professional capacities, as the very fact that a clinician is not in the position of the patient enables him to be of help.

Apart from identification, empathy may also be confused with positive counter-transference. Counter-transference can be defined as an inter-personal experience with roots in the clinician's "past." For example, the abovementioned past history of the melanoma induced in the oncology clinician a negative counter-transference. Strong emotions because of counter-transference may influence the clinician's judgment and, for example, prevent him from accepting the transition from curative to palliative treatment. Even more problematic is the phenomena of "collusion," which is an (unconscious) regression to an unresolved problem, shared by the patient and the clinician [7]. The situation presented in the abovementioned supervision can be interpreted as a collusion between patient and clinician, both of them struggling with an unresolved problem concerning autonomy. The oncology clinician partly lost her autonomy by her illness and had to heavily rely on others ("If I wouldn't have followed the doctors' advice, I wouldn't be alive anymore") but behaved like "business as usual" and thus ignored her limited autonomy. On the other hand, the elderly patient also partly lost her autonomy and attempted to regain it by refusing pain medication, challenging the clinician's freedom to act and thus toughed the very sensitive, unresolved issue. One can therefore understand the strong reaction of the oncology clinician as a phenomena of collusion.

To differentiate between empathy, identification, countertransference and collusion is important to reduce distress and may be clarified through participation in so-called Balint groups or supervisions.

\section{Early development and life trajectory_ " "the past is shaping the present"}

The importance of early development and life trajectory is illustrated by a study by Eliott and Guy [8], who investigated 340 female mental health professionals and compared them to 2,623 women of other professions. They found higher rates of reports of physical abuse, sexual molestation, parental alcoholism, psychiatric hospitalisation of a parent, death of a family member and family dysfunction in the mental health professionals and concluded: parentified children internalise a caretaking role and later fulfil by means of their profession their need of closeness and intimacy that were not met in childhood. Paris and Frank [9] evaluated 301 male medical and 246 male law students. After eliminating those who chose the same occupation as their parents, medical students were more likely to have experienced illness in their family. The authors concluded that "reparation" of traumas of childhood is dealt within adulthood by giving to others what one would have wanted to give or be given as a child.

It is important for health care professionals to reflect on their own development, which are powerful motors for motivation and success, but unresolved issues related to one's trajectory may also catch the clinician in an "impossible mission," which will exhaust him. If acknowledged, unresolved issues can be worked through and integrated, as an example may serve again this supervision of the oncology clinician. She reported in the fourth session that as a child, she often had daydreams of saving peers who were run over by a car on their way to school. She then linked these daydreams to an impression that - despite her efforts and successes - her achievements never seemed to satisfy her parents and she remembered coming home as a future physician with very good final exams, still feeling of not having done enough to satisfy her parents. She linked these daydreams and souvenirs to her current situation in which she often felt inadequate, hunted by an ideal representation of her profession and an inability to accept her limits. She then expressed how much her illness has her affected and left her with a feeling of not being able anymore to plan her personal and professional future. Her 
compensating strategies of the past- - to achieve as much as possible to keep on fulfilling the impossible mission to feel accepted and rewarded by her parents-seemed to have turned into a destructive weapon against herself.

\section{Conflicting identities-"to help and to be helped"}

Caring for others, caring for oneself and to be cared for are different situations, which require different states of mental. The clinicians' identity is focused on helping others as a central element of the profession they chose. If the professional identity is rigid, for example because of unreflected ego ideals and career choices, it might hamper the necessary insight to accept help when needed. If the transition of a clinician to become a patient seems complicated or even impossible, it might be beneficial to reflect on these issues with a mental health professional. In the case of the abovementioned oncology clinician, she finally perceived that she needed help to overcome the trauma of her disease and to analyse how the past is shaping her present. To increase her autonomy and to liberate herself from the many constraints she lived with, she decided to enter psychotherapy.

\section{Conclusions}

Current research and institutional efforts of support for the clinicians focus on external stressors of the health care professional. However, in many situations, intra-psychic stressors might be easier to identify and to diminish, thus providing effective and long-lasting support for the clinician, especially of the oncology clinicians, who is constantly exposed to situations, which might trigger intensive psychological reactions. The further development and research of consultation-liaison psychiatry is a key to gain more insight into these intra-psychic stressors and to respond with an adequate and, consequently, individualized support.

\section{References}

1. Ramirez AJ, Graham J, Richards MA, Cull A, Gregory WM (1996) Mental health of hospital consultants: the effects of stress and satisfaction at work. Lancet 347:724-728

2. Shanafelt T, Chung H, White H, Lyckholm LJ (2006) Shaping your career to maximize personal satisfaction in the practice of oncology. J Clin Oncol 24:4020-4026

3. Graham J, Ramirez A (2002) Improving the working lives of cancer clinicians. Eur J Cancer Care 11:188-192

4. Favre N, Despland JN, De Roten Y, Drapeau M, Bernard M, Stiefel F (2007) Psychodynamic aspects of communication skills training: a pilot study. Support Care Cancer 15:333-337

5. Holmes J (2002) Good doctor, bad doctor. BMJ 325:722-723

6. Winnicott DW (1951) Transitional objects and transitional phenomena. Travistock, London

7. Gabbard GO (1994) Psychodynamic psychiatry in clinical practice. The DSM-IV edition. American Psychiatric, Washington, DC

8. Eliott DM, Guy JD (1993) Mental health professionals versus nonmental health professional: childhood trauma and adult functioning. Prof Psychol Res Pract 24:83-90

9. Paris J, Frank H (1983) Psychological determinants of a medical career. Can J Psychiatry 28:354-357 